\title{
Comparative Study of Antimicrobial Effects of Lemon Oil and Peel Extract against Food-Spoilage Microbes
}

\author{
Sneh Gupta ${ }^{1}$, Charu Gupta ${ }^{2 *}$, Dhan Prakash ${ }^{2}$ and Amar P. Garg ${ }^{3}$ \\ ${ }^{1}$ Department of Zoology, RG (PG) college, Chippi Tank, Meerut-250001 (India) \\ ${ }^{2}$ Amity Institute for Herbal Research \& Studies, Amity University UP, Sector-125, Noida-201313, India \\ ${ }^{3}$ Dept. of Microbiology, CCS University campus, Meerut-250004 (India)
}

Received: April 17, 2017; Accepted: September 21, 2017; Published: October 11, 2017

*Corresponding author: Charu Gupta, Amity Institute for Herbal Research \& Studies, Amity University UP, Sector-125, Noida-201313, India, Email: charumicro@gmail.com

\begin{abstract}
The aim of the present investigation was to assess and compare the antimicrobial activities of the lemon (Citrus sinensis) peel extract and lemon oil against common food borne pathogens and to study their potential as food bio-preservatives. The antagonistic activity of lemon peel extract and lemon oil was studied against common food borne pathogens like Staphylococcus aureus, Staphylococcus epidermidis, Bacillus cereus, Bacillus subtilis, Bacillus sp. , Listeria monocytogenes, Micrococcus luteus, Escherichia coli, Klebsiella sp. and Pseudomonas aeruginosa by agar well diffusion assay. The fungal species were Rhizopus sp., Rhizomucor sp., Aspergillus fumigatus, Alternaria sp., Aspergillus niger, Aspergillus sp. and Penicillium sp. It was found that amongst bacteria, Staphylococcus aureus followed by S. epidermidis and Bacillus subtilis (with an inhibition zone diameter of $14 \mathrm{~mm}, 12 \mathrm{~mm}$ and $12 \mathrm{~mm}$ respectively) was most sensitive towards lemon peel extract; amongst fungus, the lemon peel extract was most effective against Alternaria sp., and Rhizopus sp. (with an inhibition zone diameter of $25 \mathrm{~mm}$ and $16 \mathrm{~mm}$ respectively). In contrast, the lemon oil exhibited wide range of antimicrobial activity against both groups of bacteria (maximum zone of inhibition against Bacillus mycoides and other Bacillus cereus $33 \mathrm{~mm}$ and $29 \mathrm{~mm}$ respectively) and against fungi Rhizopus sp., and Aspergillus sp. (33mm and $27 \mathrm{~mm}$ respectively).
\end{abstract}

Thus the above study depicts that antimicrobial activity of lemon oil is much better than its lemon peel extract and has potential to be used as food bio preservative.

Keywords: Lemon peel; Lemon oil; Antimicrobial; Food spoilage bacteria; Waste-management

\section{Introduction}

Throughout history and across the globe, the plant kingdom has provided a variety of medicines. In modern times, plants have been a source of analgesics, anti-inflammatory, anti-neoplastic drugs, and medicines for asthma, anti-arrhythmic agents, and anti-hypertensive. Plants with antimicrobial activity are also known to be numerous, yet prior to a decade ago, minimal research had been conducted in the area of herbal preparations as food bio-preservatives. The search for novel antimicrobial agents relies in great part on ethno-botanical information and ethno pharmacological exploration.

The antimicrobial properties of plant extracts, volatile oils and their constituents from a wide variety of plants have been assessed and reviewed [15,14,10,11,17,1,12,13]

Gould has emphasized the possible use of spices and derivatives like alternatives for inclusion in a new perspective of food conservation called "natural anti-microbial system", which could use the synergistic effect of antimicrobial compounds from animal, plant and/ or microbial origin, more physical procedures in order to create an inhospitable environment for microbial survival in foods [9].Citrus is genus of flowering plants in the family Rutaceae, native to tropical and subtropical areas in Southeast Asia. Citrus fruits have peculiar fragrance partly due to flavonoids and limonoids present in the peel and these fruits are good sources of vitamin C and flavonoids [24]. The antioxidant/ radical scavenging capacity and reducing power ability of different extracts of orange peel were investigated and results showed that ethanolic extract showed the highest values for yield i.e. total phenolic content, total flavonoid content, chelating and antioxidant activities (\% DPPH scavenging activity). It was also observed that solvent played a vital role in the extraction of the plant constituents, specifically, methanol and ethanol were highly polar among the solvents used [16]. It is also found to have antifungal activity [27].

Lemon (Citrus sinensis) peel is an agri-horticultural waste produced in large quantities from various fruit processing industries. It is normally discarded and dumped in the environment that can create environmental concerns [23]. 
Citrus by-products, if utilized fully, could be major sources of phenolic compounds. The peels, in particular, are an abundant source of natural flavonoids, and contain higher amount of phenolics compared to the edible portions. It has been reported that the contents of total phenolics in peels of lemons, oranges, and grapefruit were $15 \%$ higher than those in the peeled fruits [24].

Flavonoids in citrus are a major class of secondary metabolites. The peel contains the highest amount of flavonoids than other parts and those flavonoids present in citrus fruits belong to six peculiar classes according to their structure. They are: flavones; flavanones; flavonols; is of lavones; anthocyanidins and flavanols [24].

Flavonoids from citrus that have been extensively studied for anti-oxidative, anti-cancer, anti-viral, and anti-inflammatory activities, effects on capillary fragility, and an observed inhibition of human platelet aggregation. Recent research suggests that citrus fruits possess another health benefit phytochemicals called limonoids, highly oxygenated triterpenoid. Citrus limonoids appear in large amounts in citrus juice and citrus tissues as water soluble limonoid glucosides or in seeds as water insoluble limonoid aglycones. The limonoid aglycones are responsible for the development of delayed bitterness in citrus and are converted to the non bitter limonoid glucosides during fruit maturation [23].

In this context, studies on the antimicrobial effect of lemon peel extract and lemon oil were carried out against ten bacterial strains (7 Gram-positive and 3 Gram-negative) and seven fungi known to cause food spoilage.

\section{Materials and Methods}

\section{Materials}

All chemicals used were of analytical-reagent grade and obtained from E. Merck (Mumbai, India). Lemon peel (Citrus limon) was collected from local juice vendors of Meerut (India) and identified by Dr. C.M Govil, Botany Department, C.C.S University, Meerut, India. The lemon oil was purchased from the authorized local vendor of Meerut (India).

\section{Bacterial and fungal strains}

Ten bacterial strains (7 Gram positive and 3 Gram negative), mostly food borne including pathogens, were selected for the study. Gram positives were Bacillus cereus, B. mycoides, B. subtilis, Micrococcus luteus, Staphylococcus aureus, S. epidermidis and Listeria monocytogenes while Gram negatives were Escherichia coli, Enterobacter aerogenes and Pseudomonas aeruginosa. The fungal species used in the present study were Alternaria sp., Aspergillus fumigatus, A. niger, Aspergillus sp., Penicillium sp., Rhizopus sp. and Rhizomucor $s p$. The standard bacterial and fungal stock cultures were obtained from the culture collection of Institute of Microbial Technology (IMTECH), Chandigarh, India. The viability tests for each isolate were carried out by resuscitating the organism in nutrient agar medium and Sabouraud's Dextrose Agar (SDA) medium respectively. The stock on nutrient agar medium (Hi Media, Mumbai, India) and potato dextrose agar medium was incubated for $24 \mathrm{~h}$ at $37^{\circ} \mathrm{C}$ (bacteria) and $28^{\circ} \mathrm{C}$ for 3 days (fungi) respectively following refrigeration storage at $4^{\circ} \mathrm{C}$ until required for sensitivity testing.

\section{Preparation of lemon peel extract}

The lemon peels were obtained from the local juice vendors in Meerut (UP). The peels were sorted, cleaned and washed in sterile distilled water. The herbal extract was prepared by dissolving $1 \mathrm{~g}$ of lemon peel in $5 \mathrm{ml}$ of solvent ( $50 \%$ aqueous-ethanol) in a $250 \mathrm{~mL}$ Erlenmeyer flasks. The aqueous-ethanol (50\%) was found to be the best solvent for extracting the biologically active phyto chemical constituents from tamarind pulp. The other solvents were also used including chloroform, petroleum ether, isopropanol, ethanol and water.

The flasks were closed with cotton plug and aluminium foil. The lemon peel was soaked in $50 \%$ aqueous-ethanol for $48 \mathrm{~h}$ at room temperature with intermittent shaking. The mixture was centrifuged at $3500 \mathrm{X}$ g for $20 \mathrm{~min}$ and finally filtered through Whatmann filter paper No.1 [2]. The pellet was discarded and the supernatant was collected and concentrated under reduced pressure in a rotary vacuum evaporator (Buchi Type) until semisolid residue was obtained. This was dried inside the crucible under a controlled temperature $\left(45^{\circ} \mathrm{C}\right)$ to obtain solid powder [18]. The process of extraction was repeated until the weight of $500 \mathrm{mg}$ was obtained.

The powder was weighed and reconstituted in Dimethyl Sulfoxide (DMSO) and were sieved through a fine mesh cloth and sterilized using a membrane filter (0.45-micron sterile filter). This extract was considered as the $100 \%$ concentration. These were stored in the refrigerator at $4{ }^{\circ} \mathrm{C}$ for testing antimicrobial sensitivity.

\section{Antibacterial activity testing using agar well method (cup plate method)}

The antimicrobial activity of lemon peel extract was determined by agar well diffusion method [22]. Pure isolate of each bacterium was first sub cultured in nutrient broth at $37^{\circ} \mathrm{C}$ for $24 \mathrm{~h}$. One hundred microlitres $(100 \mu \mathrm{L})$ of standardized inoculum (106CFU/mL; 0.5 Mac-Farland) of each test bacterium was spread with the help of sterile spreader on to a sterile MullerHinton Agar plate (Hi Media, Mumbai, India) so as to achieve a confluent growth. The plates were allowed to dry and a sterile cork-borer $(6.0 \mathrm{~mm}$ diameter) was used to bore wells in the agar. Subsequently, a $50 \mu \mathrm{L}$ volume of the extract was introduced in triplicate wells of the agar plates. Similarly, $50 \mu \mathrm{L}$ volume of the lemon oil was also introduced in triplicate wells of the agar plates. Sterile DMSO and sodium propionate (standard food preservative) served as negative and positive control respectively for both the studies. The plates were allowed to stand for $1 \mathrm{~h}$ or more for diffusion to take place and then incubated at $37^{\circ} \mathrm{C}$ for $24 \mathrm{~h}$. The zone of inhibition was recorded to the nearest size in $\mathrm{mm}[21]$. All the experiments were performed in triplicate. 


\section{Antifungal assay}

For determining the antifungal activity of the lemon peel extract and lemon oil, the fungal isolates were sub-cultured on SDA at $28^{\circ} \mathrm{C}$ for 3-5 days. Sterilized Sabouraud's Dextrose Agar plates were taken and a sterile cork-borer (6-mm diameter) was used to bore wells in the agar. $50 \mu \mathrm{L}$ volume of the extract and oil was introduced into each of the peripheral wells while a fungal disc was inoculated into the central well. A negative control (sterilized DMSO) was also included in one of the peripheral wells to compare the activity. The plates were then incubated at $28^{\circ} \mathrm{C}$. The evaluations were carried out by means of daily measurement of colony diameter, starting $24 \mathrm{~h}$ after the experiment began and finishing when $2 / 3$ rd the plate surface of the control treatment was covered by the fungus [7]. The appearance of zones of inhibition was regarded as the presence of antimicrobial action in the test substance. All the experiments were performed in triplicate.

The results were expressed in terms of the diameter of the inhibition zone: $<9 \mathrm{~mm}$, inactive; $9-12 \mathrm{~mm}$, partially active; 13 $18 \mathrm{~mm}$, active; $>18 \mathrm{~mm}$, very active (Junior and Zanil, 2000).

\section{Assessment of Minimum Inhibitory Concentration (MIC)}

The method of Thongson was applied [26]. The MIC for the crude extract was determined by agar-well diffusion method. A two-fold serial dilution of the test extracts was prepared by first reconstituting it in DMSO. It was then diluted in sterile DMSO to achieve a decreasing concentration range of $1000-31.25 \mathrm{mg} /$ $\mathrm{mL}$. A $50 \mu \mathrm{L}$ volume of each dilution was added aseptically into Mueller Hinton agar plates that were already seeded with the standardized inoculum $(106 \mathrm{CFU} / \mathrm{mL})$ of the test bacterial cells. Sodium propionate was used as positive control. All the experiments were performed in triplicate. The same procedure was used for fungi, except that SDA plates were used and the plates were incubated at $28^{\circ} \mathrm{C}$. The lowest concentration of tamarind extract showing a clear zone of inhibition was considered as the MIC.

\section{Results}

A total of ten bacterial species and seven fungal species have been used in the present study to assess the antimicrobial activity of aqueous-ethanolic extract of lemon peel \& lemon oil. The antimicrobial activity of the extract was determined by agar well diffusion method. (Table 1) shows the comparison in antimicrobial activity of the lemon peel extract and lemon oil against seven Gram positive bacteria and three Gram negative bacteria. The extract was partially active against both Gram-positive and Gram-negative bacteria except Listeria monocytogenes that were isolated from the spoiled food products.

Table1: Zone of inhibition (mm) of ethanolic extract of lemon peel and lemon oil (Citrus limon) on selected bacteria that cause food spoilage

\begin{tabular}{|c|c|c|c|c|}
\hline Bacterial species & Lemon peel extract & Lemon oil & Sodium propionate (+veC) & DMSO(-veC) \\
\hline Bacillus cereus & 11.0 & 29.0 & 15.0 & 0.0 \\
\hline Bacillus subtilis & 12.0 & 13.0 & 14.0 & 0.0 \\
\hline Bacillus mycoides & 11.0 & 33.0 & 21.0 & 0.0 \\
\hline Staphylococcus aureus & 14.0 & 16.0 & 15.0 & 0.0 \\
\hline Staphylococcus epidermidis & 12.0 & 17.0 & 13.0 & 0.0 \\
\hline Listeria monocytogenes & Partly & 13.0 & 15.0 & 0.0 \\
\hline Micrococcus luteus & 11.0 & 21.0 & 18.0 & 0.0 \\
\hline Escherichia coli & 10.0 & 11.0 & 12.0 & 0.0 \\
\hline Enterobacteraerogenes & 10.0 & 10.0 & 11.0 & 0.0 \\
\hline Pseudomonas aeruginosa & 10.0 & Partly & 12.0 & 0.0 \\
\hline
\end{tabular}

The aqueous-ethanolic extract of lemon peel was most effective against Staphylococcus aureus followed by Staphylococcus epidermidis and Bacillus subtilis (with an inhibition zone diameter of $14 \mathrm{~mm}, 12 \mathrm{~mm}$ and $12 \mathrm{~mm}$ respectively). Sodium propionate (commonly used food preservative) was used as a positive control in the study and it was less effective producing an inhibition zone of diameter of 15.0, 13.0 and $14.0 \mathrm{~mm}$ respectively.

In contrast, the lemon oil exhibited wide range of antimicrobial activity against both groups of bacteria. The maximum zone of inhibition was observed against Bacillus mycoides and Bacillus cereus producing $33 \mathrm{~mm}$ and $29 \mathrm{~mm}$ Inhibition Zone Diameter (IZD) respectively.
Amongst the Gram negative bacteria, the lemon peel extract showed equivalent activity against all the test bacteria Pseudomonas aeruginosa, Escherichia coli and Enterobacter aerogenes with IZD of $10.0 \mathrm{~mm}$ each whereas lemon oil also exhibited partial activity against the same.

Antifungal effects of the lemon peel extract and lemon oil have also been investigated as shown in (Table 2). All the seven test fungi were isolated from the spoiled food products.

Amongst fungus, the lemon peel extract was most effective against Alternaria sp. and Rhizopus sp. with an inhibition zone diameter of $25 \mathrm{~mm}$ and $16 \mathrm{~mm}$ respectively while the other test fungi were almost resistant to it. 
Table 2: Zone of inhibition (mm) of ethanolic extract of lemon peel and lemon oil (Citrus limon) against common food spoilage fungi on SDA medium

\begin{tabular}{|c|c|c|c|c|}
\hline Fungal species & Lemon peel extract & Lemon oil & Sodium Propionate (+ve C) & DMSO (-ve C) \\
\hline Aspergillus niger & 0.0 & 20.0 & 18.0 & 0.0 \\
\hline Aspergillus fumigates & 0.0 & 25.0 & 22.0 & 0.0 \\
\hline Aspergillus sp. & 8.0 & 27.0 & 23.0 & 0.0 \\
\hline Alternaria sp. & 25.0 & 0.0 & 24.0 & 0.0 \\
\hline Rhizomucor sp. & 0.0 & 22.0 & 20.0 & 0.0 \\
\hline Rhizopus sp. & 16.0 & 33.0 & 18.0 & 0.0 \\
\hline Penicillium sp. & 0.0 & 0.0 & 11.0 & 0.0 \\
\hline
\end{tabular}

Contrary to this, lemon oil exhibited antagonistic activity against almost all test fungi. It was most effective against fungi Rhizopus sp., and Aspergillus sp. with an IZD of $33 \mathrm{~mm}$ and $27 \mathrm{~mm}$ respectively.

The MIC for the fungal species was therefore not determined. In contrast, sodium propionate which is used as a standard food preservative inhibited all the test fungal species.
(Table 3) depicts the Minimum Inhibitory Concentration (MIC) of the lemon oil. It ranged from 6.25 to $50 \mathrm{mg} / \mathrm{mL}$. Staphylococcus aureus and Micrococcus luteus was found to be highly sensitive to the extract exhibiting lowest MIC of $6.25 \mathrm{mg} / \mathrm{mL}$ each followed by Bacillus cereus and Bacillus mycoides (MIC= $12.5 \mathrm{mg} / \mathrm{mL}$ each).

Table 3: The MIC (Minimum inhibitory concentration) values of lemon oil (Citrus limon) (mg/mL) against different bacteria on Mueller- Hinton Agar Medium

\begin{tabular}{|c|c|c|}
\hline Bacterial species & Lemon oil ( $\mathbf{m g} / \mathbf{m L})$ & Sodium Propionate $(\mathbf{m g} / \mathbf{m L})$ \\
\hline Bacillus cereus & 12.5 & 12.5 \\
\hline Bacillus subtilis & 50 & 25 \\
\hline Bacillus mycoides & 12.5 & 12.5 \\
\hline Staphylococcus aureus & 6.25 & 12.5 \\
\hline Staphylococcus epidermidis & 25 & 25 \\
\hline Listeria monocytogenes & 50 & 6.25 \\
\hline Micrococcus luteus & 6.25 & 25 \\
\hline Escherichia coli & 50 & 25 \\
\hline Enterobacteraerogenes & 50 & 50 \\
\hline Pseudomonas aeruginosa & -- & 25 \\
\hline
\end{tabular}

\section{Discussion}

The observed antimicrobial activity was probably due to combination of more than one constituent. The various components may act synergistically $[6,8]$.

From these studies, it was observed that although lemon peel is effective against both groups of bacteria but its activity was high in Gram positive bacteria as compared to Gram-negative bacteria. These observations are in accordance with the earlier observations reported by and they also reported that Gramnegative organisms were less susceptible to the herbal extracts than Gram-positive isolates [3,5]. It may possibly be due to the presence of high lipid content in the cell walls of Gram negative bacteria. Gram-positive bacteria such as Staphylococcus epidermidis, Staphylococcus aureus, and Bacillus subtilis contains teichoic acid in the peptidoglycan layer and is therefore inhibited by both lemon peel extracts and lemon oil [19]. Furthermore, the outer membrane of Gram-negative bacteria is known to present barrier to penetration of numerous antibiotic molecules, and the periplasmic space contains enzymes, which are capable of breaking down foreign molecules introduced from outside thus providing greater resistance to them [4].

This could be also attributed to their higher percent of oxygenated compounds and sesquiterpenes as the results of GC/ MS revealed. The observed cytotoxic activity of peels essential oils may be attributed to the presence of limonene, $\propto$-pinene, 
$\beta$-myrecene and caryophyllene which had been previously proved to be the cytotoxic components in other essential oils [25]. Other constituent viz. $\beta$-pinene, $\alpha$ - terpineol, $\gamma$-terpinene and trans- $\alpha$ bergamotene may have synergistic effects with limonene [20].

\section{Conclusion}

Processing of citrus by-products potentially represents a rich source of phenolic compounds and dietary fiber, owing to the large amount of peel produced. These citrus fruit residues, which are generally discarded as waste in the environment, can act as potential antimicrobial agents. Besides, due to their low cost and easy availability such wastes are also capable of offering significant low-cost nutritional dietary supplements. The utilization of these bioactive rich citrus residues can provide an efficient, inexpensive, and environment friendly platform as source of food preserving agents. The above study showed that both lemon peel and lemon oil exhibit good antagonistic activity against food spoilage bacteria and fungi. However, further research on the use of other botanical extracts can be rewarding to pursue in hunt for new herbal therapeutic agent. However, the effect of lemon oil and their peel extract on more pathogenic organisms and toxicological investigations and further purification, still needs to be carried out.

\section{References}

1. Arora D and Kaur J. Antimicrobial activity of spices. Int J Antimicrob Agents. 1999;12(3):257-262.

2. Azoro C. Antibacterial activity of crude extract of Azadirachita indica on Salmonella typhi. World Journal of Biotechnology. 2000;3:347-351.

3. Desta B. Ethiopian traditional herbal drugs. Part II. Antimicrobial activity of 63 medicinal plants. J Ethnopharmacol. 1993;39(2):129 139

4. Duffy CF and Power RF. Antioxidant and antimicrobial properties of some Chinese plant extracts. Int J Antimicrob Agents. 2001;17(6):527529.

5. Escalona-Arranz JC, Peres-Roses R, Urdaneta-Laffita I, Camacho-Pozo MI, Rodrigues-Amado J and Licea-Jiminez I. Antimicrobial activity of extracts from Tamarindus indica L. leaves. Pharmacogn Mag. 2010; 6(23):242-247. doi: 10.4103/0973-1296.66944

6. Espina L, Somolinos M, Lorán S, Conchello P, García D and Pagán R Chemical composition of commercial Citrus fruit essential oils and evaluation of their antimicrobial activity acting alone or in combined processes. Food Control. 2011; 22(6):896-902

7. Fiori ACG, Schwan-Estrada KRF, Stangarlin JR, Vida JB, Scapim CA, Guz MES, et al. Antifungal activity of leaf extracts and essential oils of some medicinal plants against Didymella bryoniae. Journal of Phytopathology. 2000;148(7-8):483-487. doi: 10.1046/j.1439$0434.2000 .00524 . x$

8. French RC. The bio-regulatory action of flavor compounds on fungal spores and other propagules. Annual Review of Phytopathology 1985;23:173-199.

9. Gould GW. Industry perspective on the use of natural antimicrobials and inhibitors for food application. J Food Prot. 1996; 59(13):82-86 doi: 10.4315/0362-028X-59.13.82

10. Gupta C, Garg AP and Gupta S. Antimicrobial and Phytochemical studies of fresh ripe pulp and dried unripe pulp of Mangifera indica(Amchur) Middle- East Journal of Scientific Research. 2010;5(2):75-80.
11. Gupta C, Garg AP and Uniyal RC. Antibacterial activity of Amchur (dried pulp of unripe Mangifera indica) extracts on some indigenous oral microbiota causing dental caries. Ethnobotanical Leaflets. 2009;2009(5):611-617.

12. Gupta C, Garg AP, Uniyal RC and Kumari A. Comparative analysis of the antimicrobial activity of cinnamon oil and cinnamon extract on some food-borne microbes. African Journal of Microbiology Research. 2008;2(9): 247-251.

13. Gupta C, Garg AP, Uniyal RC and Kumari A. Antimicrobial activity of some herbal oils against common food borne pathogens. African Journal of Microbiology Research. 2008;2:258-261.

14. Gupta C, Kumari A, Garg AP, Catanzaro R and Marotta F. Comparative study of cinnamon oil \& clove oil on some oral microbiota. Acta Biomed. 2011;82(3):197-199.

15. Gupta C, Prakash D and Gupta S. Studies on the antimicrobial activity of Tamarind (Tamarindus indica) and its potential as food biopreservative. International Food Research Journal. 2014;21(6):24372441.

16. Hegazy AE and Ibrahium MI. Antioxidant Activities of Orange Peel Extracts. World Applied Sciences Journal. 2012;18(5):684-688. doi: 10.5829/idosi.wasj.2012.18.05.64179

17. Jantan I, Yassin M, Chin C, Chen L and Sim N. Antifungal activity of the essential oils of nine Zingiberaceae species. Pharmaceutical Biology. 2003;41(5):392-397.

18. Jonathan SG and Fasidi IO. An Original Article on Antimicrobial activities of two Nigerian edible macro-fungi Lycoperdonpusilum and Lycoperdongiganteum. African Journal of Biomedical Research. 2003;6:85-90

19. Matejko I and Scaglione A. Antimicrobial effects of spice extracts on three species of bacteria Woodrow Wilson Summer 2000. Institute on Biodiversity. 2000.

20. Monajemi R, Oryan S, Roohani A, Ghannadi A and Jafarian A. Cytotoxic effects of essential oils of some Iranian Citrus peels. Iranian Journal of Pharmaceutical Research. 2005;4:183-187.

21. Norrel SA and Messley KE. Microbiology Laboratory Manual Principles and Applications Prentice Hall, Upper Saddle River, New Jersey, 1997.

22. Okeke MI, Iroegbu CU, Eze EN, Okoli AS and Esimone CO. Evaluation of extracts of the root of Landolphia owerrience for antibacterial activity. J Ethnopharmacol. 2001;78(2-3):119-127

23. Rafiq S, Kaul R, Sofi SA, Bashir N, Nazir F and Nayik GA. Citrus peel as a source of functional ingredient: A review. Journal of the Saudi Society of Agricultural Sciences. 2016.

24. Sawalha SMS, Arráez-Román D, Segura-Carretero A and FernándezGutiérrez A. Quantification of main phenolic compounds in sweet and bitter orange peel using CE-MS/MS. Food Chemistry. 2009;116(2):567-574.

25. Stephen M and Duke JA. CRC Handbook of Medicinal Mints. Library of Congress, CRC Press, Inc. Boca Raton, New York, London and Tokyo, 1996

26. Thongson C, Davidson PM, Mahakarrchanakul W and Weiss J. Antimicrobial activity of ultrasound assisted solvent extracted spices. Lett Appl Microbiol. 2004; 39(5):401-406.

27.Velázquez-Nuñez MJ, Avila-Sosa R, Palou E and López-Malo A Antifungal activity of orange (Citrus sinensis var. Valencia) peel essential oil applied by direct addition or vapor contact. Food Control. 2013;31(1):1-4 